\title{
Social Capital and Social Trust in Britain
}

\author{
Yaojun Li, Andrew Pickles and Mike Savage
}

Most quantitative research in social capital focuses on civic engagement in formal organisations. Data on social capital in informal social networks are harder to obtain and there has also been insufficient means for investigating this. In this paper, we use the British Household Panel Survey (BHPS) to conceptualise and measure three types of social capital: neighbourhood attachment, social network and civic participation. The first two refer to informal social networks and the last to formal social networks. We use gllamm (Generalized Linear Latent and Mixed Models) to construct the latent variable scores from the categorical component variables. We also analyse the socio-cultural determinants of the three types of social capital and their impacts on social trust. The results show that socio-cultural conditions affect social capital generation. People in disadvantaged positions are more likely to draw social capital from weak ties and those in advantaged positions are more likely to do so from formal civic engagement. We also find that social capital has an effect over and above people's own socio-cultural positions. Informal social networks, especially having good neighbourly relations, tend to foster greater trust than does formal civic engagement.

\section{Introduction}

The concept of social capital is seductive, but infuriating. In the hands of leading social scientists such as James Coleman $(1988,1990)$ and especially Robert Putnam (2000) the promise is held out that it can explain a remarkable range of social phenomena, from educational performance, children's welfare, economic prosperity, democracy to even 'health and happiness'. ${ }^{1}$ Yet the scope of the concept remains over-general, and the mechanisms by which it is meant to operate are underspecified. With respect to scope, there is a tension between those writers such as Bourdieu (1986) and Lin (2001), who are concerned with how social capital benefits individuals, and other writers, notably Putnam (2000), who are more interested in how it generates collective goods. With respect to the mechanisms, there is a difference between those who see the experience of engagement in civic organisations as crucial to the beneficial effects of social capital (Putnam, 2000; Anheier and Kendall, 2002), and those who emphasise that network processes (rather than associational involvement) produce social capital (Lin, 2001; Burt, 2002).

These difficulties are not surprising. The concept of social capital has emerged in an interdisciplinary space allowing unusual dialogue between neo-classical economics and other social sciences (Fine, 2001; Field, 2003), and we should not be surprised that its main theorists currently fail to agree. Nonetheless, if the concept is to be put on a firm footing and, in particular, if it is to be used as a precise means of social analysis, it is necessary to define its scope and causal properties. This paper argues that the generic concept of social capital can be broken down into three different processes, each with its own social constituencies and dynamics. We show that it is empirically possible to distinguish types of social capital 
that tap formal or informal networks and, with regard to informal networks, strong and weak ties.

Methodologically, we measure three types of social capital, assess their inter-relationships, examine their determinants, and consider their relative impact on social trust. To our knowledge, this is the first attempt to conceptualise and measure different types of social capital using British survey data. The next part of this paper develops our theoretical approach, and shows how the concept of social capital is ultimately based on a theory of social networks that needs to distinguish formal and informal processes of social involvement. This theoretical elaboration leads on to the following section where we show how it is possible to differentiate types of social capital, which map onto these theoretical differences. Next, we present our findings on the social determinants of social capital types and their impacts on social trust. The final section summarises our findings and shows how social capital can be related back to broader concerns in the sociology of stratification.

\section{Rethinking Social Capital}

There are two main ways in which social capital is held to lead to various outcomes. The first approach, associated with the work of Robert Putnam (1993), adopts a neo-Tocquevillian argument that the experience of engagement in civic associations leads people to be better able to reconcile differences and work co-operatively together. 'Good government' he writes, 'is a by-product of singing groups and soccer clubs' (1993: 176). The second approach argues that social networks - including informal networks - produce social capital through the range of contacts they generate. Thus, Lin (2001: 56) argues that social capital is 'resources embedded in one's network or associations'. Bourdieu (1993: 51) sees it as 'the aggregate of the actual or potential resources which are linked to possession of a durable network of more or less institutionalised relationships of mutual acquaintance and recognition'.

Putnam's work is the most celebrated example of the first approach. Much of his work (1993, 1995, 1996, 2000) stresses the role of formal networks in voluntary associations in generating trust, for instance in his early work on Italian politics. Here his argument is that people learn to trust each other through working together, so learning to compromise and work for common goals. Putnam's later work (2000) broadens his interest in social capital to include informal social networks. "When philosophers speak in exalted tones of "civic engagement" and "democratic deliberation", we are inclined to think of community associations and public life as the higher form of social involvement, but in everyday life, friendship and other informal types of sociability provide crucial social support' (Putnam, 2000: 95). Yet he is able to extend his definition only by losing theoretical precision about how social capital is supposed to work. He falls back on metaphors and aphorisms, such as the idea that 'bonding' social capital is a form of superglue, that bridging social capital is a form of WD40, and that there is a 'dark side' to social capital. The strength of Bowling Alone lies in its descriptive richness in using large-scale social data to study the patterns and trends in formal and informal social capital in American society, but this comes with some theoretical and methodological costs.

The second, resource-based, approach to social capital can be found in the work of Lin and Bourdieu, and does not attach particular significance to involvement in formal associations. Rather, they emphasise the mobilisation of informal personal social networks as central to social capital. In Bourdieu's work, the emphasis is on the way in which social capital is necessarily exclusive, because the networks it generates between people also involve non-ties with outsiders who are excluded from social capital. Burt's $(1992,2000,2002)$ analysis of the way that bankers who are able to cross structural holes by having contact with different cliques are advantaged over those who do not maintain such ties is an example of this approach. Similarly, Lin (2001) shows that Chinese men are better able to move into senior occupational positions than women in part because of their superior stock of social capital in the range of network ties.

To some extent the differences between these perspectives is related to the kinds of outcomes under examination. Putnam is interested in collective goods (such as high aggregate levels of well being) whereas network writers are more concerned with individual goods (such as relatively high income or position). In our view whilst the latter approach is certainly interesting in its own right, it tends to collapse the analysis of social capital into that of social relations more generally (since it leads to the familiar interest in 'who gets ahead', which lies at the heart of the sociology of stratification). Much of the excitement about the idea of social capital lies in its concern to measure collective goods (Inkeles, 2000; Stolle and Hooghe, 2003), which is the question we focus on in this paper.

In assessing the significance of these two approaches for the generation of collective goods, we should note that the significance of voluntary associations for social 
capital is contested. Some studies show little relationship between associational membership and social trust. Freitag (2003a) demonstrates no such relationship in Switzerland (though there is one in Japan: Frietag, 2003b), as does Mayer (2003) for France. Hall (1999) shows that trust has fallen in the UK, even though associational membership has remained relatively constant, a finding echoed by Paxton (1999) in the USA. ${ }^{2}$ Claibourn and Martin (2000) use panel data to argue that there is no simple causal relationship between associational membership and trust. One reason may be that contemporary involvement in voluntary associations is actually instrumental and managerial, and not likely to bestow any generalised trust (Clark et al., 2002). Szreter (2002) and Roßteutscher (2002) emphasise that associations generate social capital through their connections to political processes, and hence the causal relationship does not flow from civic involvement to democratic political culture, but rather from politics to civic involvement. Some researchers have developed a hybrid measure of social capital including both associational membership and levels of reported trust (Paxton, 2002).

In short, it seems unlikely that social capital defined as associational involvement will be particularly powerful in generating outcomes such as social trust (Molenaers, 2003; Stolle, 2003). However, when broadening the definition of social capital to include informal network processes, as Putnam does (see more generally Portes, 1998; Field, 2003), we need to think carefully about how such processes might actually generate trust. It is particularly important to distinguish between the resources mobilised through weak ties and strong ties (Granovetter, 1973; Lin et al., 1981). Weak ties of acquaintances such as neighbours or work colleagues are often thought to be especially important as a resource for individuals, and might in Putnam's terms serve as bridging social capital. Strong ties of intimate friendship may be valuable in generating intense emotional support (Jamieson, 1998; Pahl, 2000), so producing bonding social capital. This kind of distinction is elaborated by Putnam as that between 'thick trust' embedded in one's intimate personal relations and 'thin trust' placed in the anonymous other (2000: 136-137). ${ }^{3}$ In order to distinguish these processes, we need to recognise the difficulty of measuring social networks through survey instruments. Ideally, social network analysis depends on data collected on whole populations, rather than samples, so that the connections between all members of the population can be ascertained. It is in this way that Burt (2002) examines the social capital of bankers, for instance. However, such strategies are not possible for the kind of national representative surveys that are usually used in quantitative research. Although it is possible to gain some information about strong ties in surveys by asking about 'best' friends, it is difficult to measure weak ties with survey data, since this requires knowing about a wide range of people's contacts. Lin (2001) uses 'position generator' questions where respondents identify whether they know people in varying social range, with those who know a greater range being defined as having more social capital. Another strategy is to examine the salience of situational networks, which assess the degree of support available for particular situations people confront in their daily life, such as amongst neighbours or parents. The resulting networks are relatively open and fluid since one cannot control whom your neighbours or parents are. When one feels close to people in the same situation, this is an indication that trust has arisen from these social networks. On the other hand, friendship networks are more likely to be exclusive in that people have the ability to define their own friends.

The network resources discussed above can thus be classified into three main conceptual types: informal personal networks, informal situational networks, and formal civic engagement. By distinguishing these types of networks we are able to explore a number of key issues. Are they bundled together in the way implied by Putnam, or are they empirically distinct? Do different social groups rely on different kinds of social networks? How do different types of social capital impact on social trust? These questions allow us to go beyond generic accounts of social capital and enable us to gain a more precise understanding than available hitherto of how social capital may become a significant social force.

\section{Measuring Social Capital}

Our three types of social capital can be summarised as follows:

Neighbourhood attachment. This refers to the degree to which people are attached to their neighbourhood, taking this as a key index of situational networks, or 'weak ties' (Granovetter, 1973; Pahl, 2000). We use questions on both attitudinal (e.g. 'I belong to the neighbourhood') and behavioural (e.g. 'Advice is available from my neighbourhood') aspects of local attachment. Although it might be objected that this makes our measure inconsistent, we will be able to tell in our factor analysis whether these items are related together. This type serves as a measure of embeddedness in one's immediate community (Harper, 2001). 
Social network. The second type of social capital seeks to measure the extent of people's intimate interaction with those beyond immediate family, and the extent to which people feel they have supportive networks. In other words, we are here trying to assess the extent of 'strong ties'. Such ties need not be based in any particular location and do not require any assumptions about geographical proximity. As with 'neighbourhood attachment', the questions cover both behavioural (e.g. 'Is there anyone you could rely on to help you from outside your own household if you needed to borrow money to pay an urgent bill like electricity, gas, rent or mortgage?') and attitudinal (e.g. 'Is there anyone who you can totally be yourself with?') aspects. A high degree of social capital in this regard may be manifested in the range and depth of social connections that may serve to integrate the actor in the social fabric of society (Pahl, 2000).

Civic participation. Existing studies generally use civic participation as sources of social capital. Most of the studies proceed either by counting the number of memberships in specific civic organisations as an index of the stock of social capital in society at a particular time (Hall, 1999; Paxton, 1999; Putnam, 2000; Li et al., 2002) or by combining certain organisations into associational types on theoretical grounds (Li et al., 2003). In this paper, we measure the level of formal social capital from the underlying scores for involvement in voluntary associations. ${ }^{4}$

We use the British Household Panel Survey (BHPS) to construct the measures of social capital dimensions. The survey began in 1991 (Wave 1) as the premier British panel study, and samples around 5000 households and 10,000 individuals each year. Although some of the original sample members dropped out in later waves, new members are added and the samples are generally representative of the UK population in each wave.

The data in the BHPS allow us to measure the types of social capital along the conceptual lines discussed above. As shown in the Appendix (available via the first author's website), ${ }^{5}$ there are eight questions of an ordinal nature for neighbourhood attachment, eight questions of an ordinal nature for social networks, and 16 questions of a dichotomous nature for civic associations. Given the categorical nature of the component variables, we use two-parameter item response theory (IRT) models (Lord and Novick, 1968) to obtain estimates of individual levels of social capital. The sets of items (component variables for each type of social capital) were selected as likely indicators of the potentially distinctive facets of social capital. With indicators for neighbourhood attachment and social networks, the original multi-category numerical codes were reordered to form natural ordered scales. The neighbourhood attachment scale was derived from eight items, each with five categories. The social network scale was derived from eight items, each with three categories. For the set of items indicating civic participation, some items reflected similar types of organisation that were rarely endorsed and were summed together, with the sum score being treated as a single ordinal item. The original 16 items were reduced to eight, six with two categories (binary), one with three categories, and one with six categories. No such summing was required for the remaining scales.

The eventual indicators in each type were thus sets of ordinal items. We then used two-parameter IRT models to obtain estimates of the underlying types of social capital. An IRT postulates that a single continuous factor underlies responses to all items within a set but that this factor is 'measured' subject to error by each item. A continuous score thus underlies each item, the sum of a true score contribution and an error. The distribution of this score is divided up by a set of ordered thresholds, with each section of the distribution being associated with observing one of the possible ordered categorical responses. A respondent's categorical score is therefore determined by their continuous score falling within a particular range of values defined by an adjacent pair of thresholds. Since the continuous score is not directly observable, it is commonly considered to be a latent variable.

However, different items within a set may have different item characteristics. Items are allowed to differ in two ways. Firstly, items may have different threshold parameters. This allows, for example, fewer people to say that they have 'no one to go to were they depressed' than 'no one to go to for borrowing money'. Secondly, items may have different sensitivity or factor loading parameters. This allows items to be strongly or weakly related to the underlying factor, or correspondingly to vary in the extent to which they measure the underlying factor rather than something else. Choosing a proportional odds ordinal logistic parameterisation allows the model to be specified by

$$
\ln \left(\frac{\operatorname{pr}\left(Y_{i j} \leq k\right)}{\operatorname{pr}\left(Y_{i j}>k\right)}\right)=\alpha_{i K}+\lambda_{i} \eta_{j}
$$

where $Y_{i j}$ is the response to item i from individual $j, \eta_{j}$ is the score of individual $j$ on the latent factor, $\lambda_{i}$ is the factor loading for item i, $\alpha_{i K}$ is the threshold for a response of $\mathrm{K}$ or above. For an item with $\mathrm{K}$ categories, 1 to $\mathrm{K}$, $\alpha=\infty$. Standard identification restrictions are necessary 
and we estimate the variance of the latent variable but constrain the first factor loading to 1 . All variables have to be measured in some units and this restriction merely implies that the latent variable is to be measured in the units of item 1. It is also usual to make some parametric assumption about the distribution of the latent variable in the population. We have assumed this to be normally distributed. ${ }^{6}$

The models were estimated by maximum likelihood in Stata using gllamm (Generalized Linear Latent and Mixed Models) (Rabe-Hesketh et al., 2000) and adaptive quadrature (Rabe-Hesketh et al., 2002). Respondents with partially incomplete sets of responses were included under the assumption of the missing data being missing at random (Rubin, 1976). Estimates of scores on the underlying factor for each individual were calculated using empirical Bayes' methods. This provided estimates both of individual scores and of estimation precision, the latter tending to be lower for those with incomplete data. The analyses indicated, with exceptions noted below, that the items within each set were indeed associated with a single dominant underlying latent variable, and that the latent variables were rather weakly correlated with each other. ${ }^{7}$ These conditions justified our approach of fitting IRT models to each item set separately.

\section{Methods and Control Variables}

The scores obtained for the three types of social capital were standardised with a mean of zero and standard deviation of one. This procedure ensures that we can directly compare the differences from one type to another when we assess both the social determinants of social capital generation and their impacts on social trust.

We use a range of socio-cultural factors both as determinants of the social capital types and as control variables in studying their impacts on social trust. These are indexed via class, education, income, gender, marital status, age and the ward-level index of social deprivation. The inclusion of the contextual factors (social deprivation) is to help ameliorate the 'atomistic fallacies' sometimes attributed to the use of individual level data (Schwartz, 1994). As some of the component variables for the social capital types are available from Wave 7 and others from Wave 8 , we take the socio-cultural variables from Wave 7. Contemporaneous measurement of explanatory and outcome variables has a number of disadvantages, notably correlated measurement error and occasion-specific confounding (Bechhofer and Paterson, 2000). To examine the impact of social capital more rigorously, we take our social trust measures from the next wave available, namely, from Wave 10.

We give a brief account here of the socio-cultural factors. A four-way Goldthorpe (Goldthorpe et al., 1987) class is used. It distinguishes the salariat (professionals, administrators and managers), the petty bourgeoisie (small proprietors with or without employees), the routine-non-manual (routine office workers, manual supervisors and lower-grade technicians), and the working class (skilled, semi-skilled and unskilled manual workers including agricultural labourers). For educational qualifications, we differentiate between first-degree or above, professional qualifications below degree such as teaching and nursing, A/O levels, and vocational or no formal qualifications. Income is measured as the standardised household mean income, which takes account of the complex household compositions and differential needs. ${ }^{8}$ We code age into four groups to stand for different life stages and we differentiate three levels of wardlevel social deprivation: affluent, intermediate and deprived. ${ }^{9}$

\section{Results}

\section{Patterns of Social Capital and their Socio-cultural Determinants}

Table 1 gives parameter estimates for the three types of social capital. Since only the factor loading parameters are commonly of interest, we do not report estimated thresholds. Our principal interests lie in the strength of evidence for an underlying dimension (given by the $z$-statistic associated with the estimated variance of the latent variable), and in the variation in the factor loadings across items. Factor loadings greater than 1 indicate that the corresponding item is more strongly associated with the latent variable than is the reference item, namely item 1. A factor loading close to zero (say, less than 0.3 ) indicates that the corresponding item does not measure this particular latent variable.

In all cases there was strong evidence of association among the items within a set explainable by an underlying latent dimension of individual variation. However, the $\mathrm{z}$-statistics showed considerable variation between sets of items. Those for neighbourhood attachment and social networks were substantially larger $(z=26.4$ and 19.4, respectively) than that for civic participation $(z=7.4)$. The neighbourhood attachment items appeared 
Table 1 Latent scores for items of the types of social capital

\section{Number of categories}

Neighbourhood attachment

I belong to this neighbourhood

Friends in my neighbourhood mean a lot Advice is available from my neighbourhood I borrow \& exchange favours with neighbours Would work to improve my neighbourhood Would remain in the neighbourhood I am similar to others in the neighbourhood I regularly stop and talk with neighbours Latent variable variance

\section{Social networks}

Anyone to listen to you when you need to talk? Anyone to help you out in a crisis? Anyone to be totally yourself with? Anyone really appreciates you as a person? Anyone to comfort you when you are very upset? Anyone outside h/h to help you if depressed? Anyone outside $\mathrm{h} / \mathrm{h}$ to help you get job? Anyone outside $\mathrm{h} / \mathrm{h}$ to lend you money? Latent variable variance

$5.44(0.206) \mathrm{z}=26.42$

$8.45(0.435) \mathrm{z}=19.43$

\author{
Civic participation \\ Pooled items \\ Political or environmental groups \\ Trade unions \\ Tenants/resident's group \\ Religious group \\ Social group \\ Sports club \\ Professional organisations \\ Latent variable variance
}

$\begin{array}{lcc}5 & 1.00 & (-) \\ 5 & 1.22 & (0.032) \\ 5 & 0.93 & (0.024) \\ 5 & 0.48 & (0.014) \\ 5 & 0.43 & (0.013) \\ 5 & 0.68 & (0.017) \\ 5 & 0.87 & (0.021) \\ 5 & 0.92 & (0.023)\end{array}$

$\begin{array}{lcc}3 & 1.00 & (-) \\ 3 & 0.99 & (0.033) \\ 3 & 0.84 & (0.029) \\ 3 & 0.87 & (0.031) \\ 3 & 1.03 & (0.036) \\ 3 & 0.52 & (0.019) \\ 3 & 0.30 & (0.012) \\ 3 & 0.34 & (0.013)\end{array}$

Source: The British Household Panel Survey (the same below).

The items for 'social networks' are taken from Questions 5 and 6 in the self-completion part of BHPS Wave 7, question wording available at pp. 144-145 from http://www.iser.essex.ac.uk/bhps/doc/pdf_versions/questionnaires/bhpsw7q.pdf; the items for 'civic participation' are available at p. 75 of the same website; and the items for 'neighbourhood attachment' are taken from Wave 8, available at p. 112 from http://www.iser.essex.ac.uk/bhps/doc/pdf_versions/questionnaires/bhpsw8q.pdf.

Pooled items in the 'civic participation' type refer to parents association, voluntary service group, other community group, women's institute, women's group, other organisation, pensioner's organisation, scouts/guides group.

to form a largely homogeneous block, although item 4 (borrowing) and item 5 (working to improve neighbourhood) appeared to be somewhat distinct. It is clear that there is no substantive difference between the behavioural and the attitudinal questions within this group.

The social network items fell into two groups. The first five items all made substantial contributions to the measurement of the underlying dimension. The last three items possessed relatively smaller factor loadings, possibly due to their rather different location within the interview schedule, and their wording that specifically referred to people outside the respondent's household. These three items were rather weakly related to the underlying dimension of this item set.

Closer inspection of the factor loadings for the civic participation items clearly shows that although items $1,2,4,5$ and 8 were clearly informative as to the underlying dimension, memberships of a trade union, social group or sports club do not measure this same dimension 
very well. The factor scores derived from this model are an effective summary of the level of participation in the other organisations, but items relating to trade unions, working-men's groups and sports clubs may be expected to have additional but distinctive impact. This provides empirical support for the division made on theoretical grounds (Hall, 1999; Li et al., 2003) that memberships in trade unions and working-men's clubs have distinctly different social class profiles, ideological orientations and political preferences. ${ }^{10}$

Table 2 shows the standardised mean score for each type of social capital by class, education, income, gender, marital status, age and ward-level social deprivation respectively. To aid interpretation, we also present significance tests of the difference of means between each category and the reference group in each explanatory variable, with the reference category taken as the last category and shown in italics. The patterns show that the scores of the social capital types are not equally distributed among social groups. For example, the salariat has a standardised score of 0.058 in neighbourhood attachment, as compared with 0.066 for the working class. The difference between the two classes in this type $(0.066$ minus $-0.058=0.124)$ is significant at the 0.001 level. The petty bourgeoisie and the routine non-manual workers are not significantly different from the working class in this regard.

Table 2 reveals some important features in the way that social groups draw on the different types of social

Table 2 Standardised mean scores of social capital types by socio-cultural factors

\section{Neighbourhood attachment}

\section{Class}

Salariat

Petty bourgeois

Intermediate

Working class

Education

Degree

Professional

A/O Levels

Vocational/None

Income

Top quartile

2nd

3rd

Bottom quartile

Gender

Male

Female

Marital status

Married

Other

Age

16-35

36-50

51-65

$66+$

Social deprivation

Affluent

Intermediate

Deprived

$-0.058^{* * *}$
0.006
0.021
0.066

$-0.198^{\star * *}$
$-0.020^{\star * *}$
$-0.091^{\star * *}$
0.176

$-0.094^{* * *}$

$-0.003^{\star *}$

0.048

0.104

$-0.094^{* * *}$
0.096

$0.131^{\star * *}$

$-0.167$
$-0.319^{* * *}$
$0.003^{* * *}$
$0.196^{* * *}$
0.358
$0.106^{* * *}$
$0.001^{* *}$
$-0.097$

\section{Social network}

$0.102^{\star * *}$
-0.142
$0.083^{\star * *}$
-0.125
$0.175^{* * *}$
$0.070^{* * *}$
$0.105^{\star * *}$

$-0.179$

$0.187^{* * *}$

$0.030^{* * *}$

$-0.085$

$-0.152$

$-0.138^{* * *}$

0.130

$-0.035^{\star * *}$
0.063

$0.226^{* * *}$

$-0.060^{* * *}$

$-0.052^{\star * *}$

$-0.224$

$0.041^{\star *}$
0.009
-0.044

Civic participation
Approx. No

$\begin{array}{lr}0.467^{\star * *} & 2568 \\ -0.130^{\star * *} & 624 \\ -0.045^{\star * *} & 2686 \\ -0.344 & 2698\end{array}$

$0.765^{* * *} \quad 851$

$0.301^{* * *} \quad 1884$

$-0.146^{* * *} \quad 2852$

$-0.247 \quad 3126$

$0.270^{* * *} \quad 2248$

$0.017^{* * *} \quad 2364$

$-0.072^{* * *} \quad 2264$

$-0.211 \quad 2074$

$\begin{array}{ll}-0.023^{*} & 4073\end{array}$

0.040

4913

5109

3863

3199

2550

1760

1477

$0.190 \quad 1477$

$0.208^{* * *} \quad 2712$

$-0.043^{* * *}$

2734

2344

Each of the other categories in a variable is contrasted with the last category (in italics), with the results of significance tests shown. ${ }^{*} P<0.05,{ }^{* *} P<0.01$ and ${ }^{* * *} P<0.001$.

Weighted data and robust standard errors are used. Owing to the large amount of data presented in the table, standard errors and the 95 per cent confidence intervals are not shown but are available on request. 
capital. The salariat tends to have weaker neighbourhood attachment, but stronger social networks than the other social classes. This finding is in line with studies of class and sociability (Allan, 1996) that claim that the middle classes tends to differentiate friends from acquaintances, whilst the working class tends to have stronger 'situational' networks in the areas of neighbouring (see also Bulmer, 1986; Allan and Crow, 1993). The salariat is especially likely to have formal networks in voluntary associations. It is now well established that there is a strong class gradient in associational membership with the salariat having greater civic involvement than the working class in Britain (Parry et al., 1992; Hall, 1999; Li et al., 2003).

The direction of the association between education and income and the social capital types is the same as that between class and social capital. Thus, the highly educated and those with top quartile incomes tend to have significantly lower scores in neighbourhood attachment than those with only vocational or no formal educational qualifications or in the bottom quartile of income, but higher scores in the other two dimensions. Given the well-known association between education, class and income, the patterns are not surprising. Secondly, for each of the dimensions, the magnitude of the educational differences in the standardised mean scores is considerably greater than that in the class comparisons, which is also true of the income differences in the two informal dimensions of social capital. People's social capital depends not only on their occupational status, but also, at least on the face of it, on the kind of cultural and economic capital they possess.

Other patterns that emerge from Table 2 are that, compared with women, men are less likely to be attached to their neighbourhood, to have strong social support mechanisms or to participate in civic organisations. Women's capacity for social networking and friendship building is widely reported (Jamieson, 1998). It appears surprising, however, that women have stronger civic participation than men, but the differences are not large. Married people have higher scores in neighbourhood attachment and civic participation, but lower scores in social network. This last aspect is not unexpected since family life precludes much of the need or opportunity for outside emotional support (Putnam, 2000). Younger people also have lower levels of neighbourhood attachment and civic engagement and higher levels of social network than older cohorts. Finally, levels of ward-level social deprivation are also closely associated with the types of social capital in an expected way. People resident in relatively affluent areas are consistently more likely than others to have higher scores in each of the three types.

The overall patterns suggest clear evidence of social stratification in the kinds of social capital that people possess, confirming the arguments of Li et al. (2003). The greatest class differences are shown between the salariat and the working class, with the former reporting high levels of civic engagement and social networking, and the latter having strong neighbourhood networks. Our findings show that, although the working class are deprived of social capital from formal institutions, they have a relatively high degree of 'situational' social capital from informal social networks.

To further check the independence of associations reported in Table 2, we simultaneously included the variables in Table 2 as explanatory variables. Table 3 again shows persistent and significant differences between the salariat and the working class in each of the dimensions, even when all other variables are controlled for. The salariat is significantly more likely than the working class to have higher scores in social networks and civic participation, but the working class is significantly more likely than the salariat to have strong neighbourhood attachment. The effects of education and income are highly significant on social networks and civic participation, but not significant on neighbourhood attachment, when the other factors are taken into account. The effects of sex, marital status, age and social deprivation are also largely significant in the three types.

Overall, Tables 2 and 3 indicate that people in more advantaged social positions, be they occupational, educational, economic or contextual (ward-level index of social deprivation), are more likely to join civic organisations and to have denser social networks whereas those in more disadvantaged positions tend to obtain social capital from situational social networks, by feeling a greater sense of belonging to, and reporting more tangible and valuable instances of help and support from, their neighbours.

\section{Social Capital, Socio-cultural Factors and Social Trust}

Let us now explore which of the three types of social capital we have delineated is of greater importance in generating the trust that social capital theorists have emphasised as the crucial dimension of social capital. If social capital is a 'social good', it will be manifested in people's propensity for social trust, that is, in the degree of trust people would place in their fellow citizens. In order to see the impact of social capital more effectively, we use trust from Wave $10 .{ }^{11}$ As trust may well reflect 
Table 3 Regression coefficients of social capital types by socio-cultural factors

\section{Neighbourhood} attachment

\section{Social network}

$$
\begin{aligned}
& -0.146^{\star * *} \\
& -0.118^{\star} \\
& -0.114^{\star * *}
\end{aligned}
$$

Working class (base)

\section{Education}

Degree

Professional

A/O Levels

Vocational/None (base)

Income

Top quartile

2nd

3rd

Bottom quartile (base)

Gender

Male

Female (base)

Marital status

Married

Other (base)

Age

16-35

36-50

51-65

66+ (base)

Social deprivation

Affluent

Intermediate

Deprived (base)
-0.089
-0.019

$-0.016$

$-0.059$

$-0.002$

$-0.039$

$-0.195^{\star * *}$

$0.223^{* * *}$

$-0.603^{* * *}$

$-0.363^{* * *}$

$-0.194^{\star * *}$ $0.107^{\star *}$

0.033

$0.075^{\star}$

$0.129^{* *}$

$0.114^{* *}$

$0.111^{\star * *}$

$0.219^{* * *}$

$0.104^{* *}$

0.051

$-0.293^{\star * \star}$

$-0.039$

$0.358^{\star * *}$

0.082

$0.128^{\star *}$

$\begin{array}{lll}0.231^{* * *} & 0.039 & 0.162^{* * *}\end{array}$

$\begin{array}{lll}0.109^{* * *} & 0.035 & 0.030\end{array}$

Civic participation

$0.362^{\star * *}$

0.091

$0.152^{\star * *}$

$0.933^{* * *}$

$0.506^{* * *}$

$0.226^{* * *}$

$0.175^{* * *}$

$0.097^{\star *}$

$0.076^{\star *}$

Constant

$\mathrm{R}^{2}$

$0.316^{\star * *}$

0.092

$-0.257^{\star \star \star}$

0.067

$-0.207^{\star \star \star}$

7065

6918

$\mathrm{N}$

(7065

Weighted data and robust standard errors are used. Owing to the large amount of data presented in the table, standard errors and the 95 per cent confidence intervals are not shown but are available on request.

${ }^{*} P<0.05,{ }^{* *} P<0.01$ and ${ }^{* * *} P<0.001$.

stable personality traits, we also control for trust drawn from Wave 8.

Table 4 shows the effects of social capital, sociocultural factors and prior levels of trust on social trust. In order to see the social capital effects more clearly, we put the standardised scores of the three types into quartile groups. We report results from a multivariate logistic regression. Three models are constructed. Model 1 shows the effects of the three types of social capital simultaneously included. Model 2 adds the effects of socio-cultural factors to terms already in Model 1.
Model 3 adds prior levels of trust (from Wave 8) to terms already in Model 2. At the bottom of the table, we also report the improvement in fit for Model 2 over Model 1, and Model 3 over Model 2. Moving from the basic to the more complex models, we can see the changes in the coefficients associated with the social capital types, and with socio-cultural factors.

Table 4 shows that, when only the types of social-capital were included (Model 1), people with higher scores in neighbourhood attachment and social network, and those in the top quartile of civic participation in particular, 
Table 4 Logistic regression on social trust by types of social capital socio-cultural factors and prior levels of trust

Model 1

Social capital dimensions

Neighbourhood attachment

Top quartile

2nd

3rd

Bottom (base)

Social network

Top quartile

2nd

3rd

Bottom (base)

Civic participation

Top quartile

2nd

3rd

Bottom (base)

$0.802^{\star * *}$

0.207

$-0.142$
Model 2

Model 3

$0.643^{\star * *}$

$0.593^{* * *}$

$0.367^{\star * *}$

$0.495^{\star * *}$

$0.476^{\star * *}$

$0.488^{* * *}$

$0.310^{\star * *}$

$0.422^{\star * *}$

$0.307^{\star * *}$

$0.264^{* *}$

$0.374^{* * *}$

$0.316^{* * *}$

$0.255^{\star *}$

$0.200^{*}$

0.130

0.112

Socio-cultural factors

Class

Salariat

Petty bourgeoisie

Routine non-manual

$0.364^{* *}$

0.181

$-0.089$

$-0.177$

$-0.217$

$-0.213$

Working class (base)

Education

Degree

Professional

A/O levels

Vocational/none (base)

Income

Top quartile

0.137

$0.555^{\star * *}$

$0.404^{* * *}$

$0.440^{* * *}$

$0.239^{* * *}$

$0.269^{\star}$

0.137

2nd

0.135

$1.073^{* * *}$

$0.332^{\star * *}$

$0.397^{\star * *}$

$0.750^{\star * *}$

$0.232^{\star}$

$0.397^{\star * *}$

3rd

0.068

0.137

0.135

Bottom quartile (base)

0.068

Gender

Male

$0.175^{*}$

$0.175^{\star}$

Female (base)

Marital status

Married

0.036

0.036

Non-married (base)

Age

16-35

36-50

$-0.293^{\star}$

$-0.293^{\star *}$

$-0.030$

$-0.030$

51-65

$-0.188$

$-0.188$

$66+$ (base)

Social deprivation

Affluent

0.157

0.157

Intermediate

$0.182^{*}$

$0.182^{*}$ 
Table 4 (Continued)

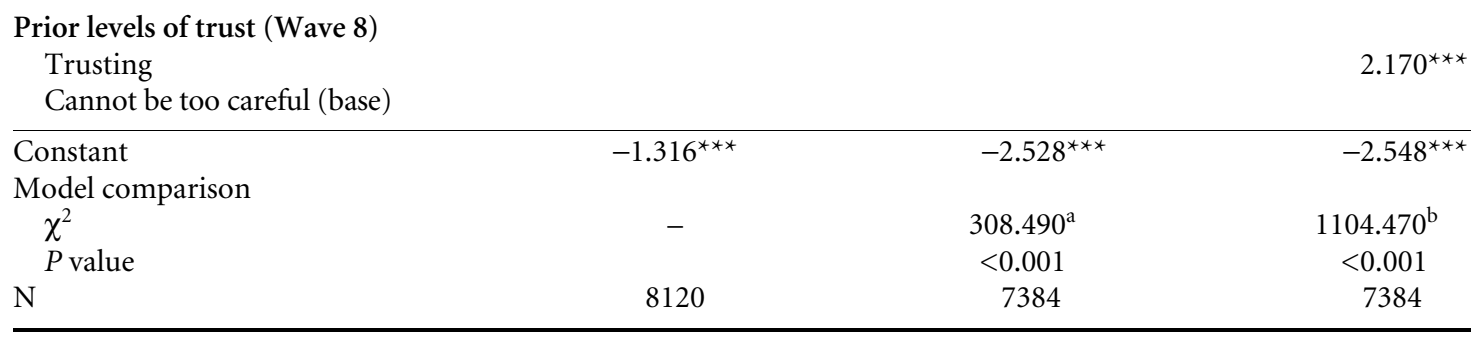

Trust in the dependant variable refers to social trust in Wave 10 (coded 'trusting' =1; 'cannot be too careful' =0). Prior levels of trust refer to trust in Wave 8. Adjusted Wald tests are used to test the additional blocks of model terms.

${ }^{a}$ Refers to terms in Model 2 that are additional to those in Model 1; ${ }^{b}$ refers to terms in Model 3 that are additional to those in Model 2.

were significantly more likely than the reference category (the bottom quartile in each type) to trust others. Looking at the coefficients for the three types, it appears that civic participation is highly generative of generalised social trust, just as Putnam suggests.

Model 2 controls for socio-cultural factors. Holding constant all other variables in the model, we find education, class, age, income, ward-level deprivation and gender are all significantly related to trust. The more advantaged one's socio-cultural position is, the more likely one tends to trust others. Young people are generally less trusting than the old, and men are more trusting than women. These patterns confirm previous analyses (Hall, 1999: 432; Putnam, 2000: 136-142). When all the other variables in the model are controlled for, education takes the greatest relative importance and marital status is the only variable which is not significant.

Our primary purpose in including the socio-cultural factors in Model 2 is to see how the coefficients of the social capital types would change as compared with those in Model 1 when none of the socio-cultural factors were included. Now, if we compare the coefficients of the social capital types from Model 1 to Model 2, we find a very interesting feature. The coefficients for neighbourhood attachment were notably increased whilst those for the other two types were sharply reduced. The coefficient for the top quartile of civic participation was more than halved: from 0.802 in Model 1 to 0.364 in Model 2. Existing research has shown that people most active in civic engagement tend to be in advantaged socio-economic positions and people in such positions are also more trusting (see, for example, Hall, 1999; Harper, 2001). Thus, controlling for socio-cultural factors rendered the effects of civic participation less prominent. On the other hand, as people in disadvantaged positions tend to have higher levels of neighbourhood attachment as we have earlier shown, controlling for socio-cultural factors made these effects more apparent.

Given, as we have earlier noted, the possibility that trust may reflect people's stable personality traits, it would be desirable to control for such traits and examine the net effects of the social capital types as we have developed. This we do in Model 3 of the table where trust from Wave 8 is used as a covariate. The patterns show that prior levels of trust have indeed the greatest relative effects, much higher than any other variables in the model. Controlling for prior levels of trust, the effects of most of the sociocultural factors were reduced, the most notable change being with education, age and income.

Now, with prior trust and socio-cultural factors held constant and comparing the change in the effects of the three social capital types from Model 2 to Model 3, we find that civic participation is no longer significant, that only the top level of social network is significant at the 0.05 level, and yet that each of the three higher levels of neighbourhood attachment is highly significant at the 0.001 level. Indeed, judging from the magnitude of the coefficients, we find that the coefficients of neighbourhood attachment were, if anything, increased from Model 1 to Model 3 where the other factors were taken into account, that the effects associated with social networks were sharply reduced, and that the greatest change occurred with civic participation where the top quartile fell from a highly significant 0.802 to a non-significant $0.181 .^{12}$ Thus, the patterns in both Model 2 and Model 3 point in the same direction, namely, that neighbourhood attachment is more important than civic participation in predicting people's social trust, with social network in between. This finding supports Putnam's (2000) speculation on the relative importance between what he calls machers and schmoozers although he did not develop any composite measures for either type. 
Before concluding, there is one very important question to ask: are the results we have reported valid, or are they merely a methodological artefact? Our component variables for neighbourhood attachment are, as earlier noted, composed of both behavioural and attitudinal responses. Is it the case that because the attitudinal questions were tapping the same basic feeling of connectedness, well-being, belonging and diffuse trust as that underlying generalised social trust, and because there is a greater weight of attitudinal questions in the set, the test in Table 4 is essentially biased, especially when we consider that the other two sets of variables are measured in an essentially behavioural way? In other words, if we had excluded the attitudinal items from the set, would we have arrived at quite different conclusions? The answer is 'no' for two reasons.

Firstly, attitudinal questions on neighbourhood attachment are no more closely related to social trust than behavioural ones. Forty-three percent of those who 'strongly agreed' that they borrow things and exchange favours with their neighbours (behavioural), as compared with 37 percent of those who 'strongly agreed' that they are similar to others in their neighbourhood (attitudinal) in Wave 8, gave a trusting response in Wave 10. Secondly, further gllamm analysis of the underlying scores with the attitudinal questions removed from the component set revealed essentially the same pattern as that reported in Table 4 . We are satisfied that our results are reassuring and not biased. ${ }^{13}$

\section{Discussion}

We have, in this paper, made a new effort at conceptualising and measuring social capital. The starting point for this is the sense that over-ambition in social capital research has led to the concept being defined in generic ways that are inattentive to the socially distinct ways in which different kinds of networks have different social determinants and different consequences. We have emphasised that the concept of social capital can be measured as three types, namely, neighbourhood attachment (mapping onto the situational social capital of weak-tie networks), social network (indicating informal, strong-tie social networks), and civic participation (representing formal social engagement). Most social capital theorists either run these together in an indiscriminative way or just focus on civic engagement as a surrogate for all kinds of social capital. We argue that there are clear theoretical reasons for differentiating civic participation involving formal communication with relative strangers, social net- works based on strong personal ties, and neighbourhood attachment indicating weak situational ties.

Our methodological advancement is to use latent response models to measure types of social capital from their categorical component variables drawn from a national representative survey. This, as far as we are aware, is a first attempt in social capital research. We can thus show not only how different types of social capital are related to various social groups, but also the direct and the indirect impacts of different types of social capital on social trust. The main findings may be summarised as follows.

First, social groups vary in the types of social capital they draw on. People in disadvantaged positions are more likely to obtain situational social capital from informal neighbourhood relations, whilst those in advantaged positions are more likely to have social capital from social networks and civic engagement. Unlike efforts for cultivating good neighbourly relations, civic participation often depends on various forms of sociocultural-economic resources and competences. Civic associations, such as professional organisations, often require their prospective applicants to formally apply for membership, pay fees, and know how to deport themselves within the organisation. This may serve to deter disadvantaged social groups from entry. Thus, if we are to avoid an incomplete, even distorted, account of social capital, we need to recognise that people in poorer socio-cultural positions may possess forms of social capital that are invisible or intangible if research is limited to involvement in formal civic institutions only. While there has been ample anecdotal evidence on this, systematic evidence has hitherto been lacking.

Secondly, various types of social capital do have a marked impact on social trust, and this effect is over and above the well-known effects of class, gender, and other socio-demographic variables in numerous aspects. In this respect our analysis is in line with Putnam (2000), and Lin (2001), in demonstrating that social capital is indeed of major importance. Thirdly, the analysis of the properties of different types of social capital in relation to social trust suggests that social capital generated from informal networks, especially from neighbourhood attachment, is of particular importance whereas that from civic participation is relatively unimportant.

It is therefore clear that we need to recognise the diversity of forms of social capital, and should not focus on formal access to civic organisations alone. Civic participation is just one out of a range of channels of social capital generation and has been amply shown to favour the middle class who, among other things, tend to be more likely than the working class to have 'the skills, the resources 
and the interests' for civic engagement (Putnam, 2000: 64). Informal social networks both with neighbours and with intimate friends beyond one's immediate neighbourhood play an important, and hitherto neglected, role at least insomuch as quantitative research using largescale and complex survey data is concerned. Registering these points will help to situate discussions about social capital within the broader parameters of debates on social stratification and inequality. In our view, this would be a welcome development.

\section{Notes}

1. These are all the subjects of chapters in Putnam (2000).

2. Putnam's arguments about declining levels of trust are qualified by Newton (1997) and Bromley et al. (2001).

3. Putnam shows four decades of 'dwindling trust' in American society which he says is explained by the generational succession (2000: 140-1). Paxton (1999) shows, however, that whilst there is some decline in trust in individuals, there is no decline in trust in institutions in the USA. See also Hall (1999: 429 ) on social trust in the UK.

4. It is noted here that the data on civic associations in the BHPS do not allow us to address issues of the 'dark side' of social capital.

5. Owing to the word limit, we have put the Appendix at the first author's website: http://www.sociology. bham.ac.uk/staff/yaojun_li.htm.

6. We have chosen not to include covariates at this stage, since here we are concerned with the measurement of social capital and covariate adjustment would correspond to adjustment for bias where we have little evidence that bias exists. For example, non-parents have restricted access to Parent-Teacher Associations (one of the participation items) suggesting that our item set is biased. However, we would argue that such PTA participation differences are not biases of measurement, but reflect real differences in access to social capital in this respect for non-parents.

7. The correlation between neighbourhood attachment and social network is 0.154 , that between neighbourhood and civic participation is 0.118 , and that between civic participation and social network is 0.086 . These coefficients can be judged as being very low (Cohen and Holliday, 1982), suggesting that the three types are fairly distinct from one another.

8. Standardised household income is constructed by taking the total household annual income before housing cost, divided by the equivalence (McClements) scale, and then put into quartiles. The income thus derived allows for the effects of household size and composition on needs in making income comparisons. This practice is often adopted by UK government agencies and by the research community (see, for example, Jenkins, 1999).

9. The ward-level index of social deprivation is based on the four characteristics drawn from the 1991 UK Census of Population: unemployment rate, percentage with no car, percentage in overcrowded housing, and percentage in lower social classes. The respondents are assigned scores with 10 categories. The categories are recoded so that $1-3=$ 'Affluent', $4-7=$ 'Intermediate' and $8-10=$ 'Deprived'. We thank Professor Nick Buck at the Institute of Social Economic Research, Essex University, for providing us with the data on this variable.

10. It is noted that we are dealing with three broad types of social capital in this paper. It is possible that a greater number of underlying factors can be differentiated. For instance, among component variables for civic participation, some organisations (such as voluntary organisations) are more likely to generate public goods than others (such as trade unions and professionals organisations). We conducted a separate analysis leaving out these two organisations. The scores with and without the two organisations have a very high correlation of 0.93 . Given this, and the fact that these and other similar organisations tend to have a public good externality, we decided to follow Putnam (2000) and Hall (1999) in keeping them in the component set for civic participation. It would also be of importance to explore people's motivations for joining specific organisations. However, the BHPS data that we use for this paper do not allow us to do this. We are very grateful to an anonymous referee for prompting us to think more deeply about this.

11. This refers to Question JV13 in Wave 10. The question reads:

Generally speaking, would you say that most people can be trusted, or that you can't be too careful in dealing with people?

$\begin{array}{ll}\text { Most people can be trusted } & 1 \\ \text { Can't be too careful } & 2 \\ \text { Other, depends (IF VOLUNTEERED) } & 3 \\ \quad \text { WRITE IN } & \\ \text { Don't know } & 8\end{array}$

As only 1.6 per cent of the respondents replied 'Other/depends', we have, following Hall (1999: 
432), dropped this and the 'Don't knows' in the analysis.

12. One may wonder whether the main effects apply uniformly or whether people in particular social positions tend to exhibit different social attitudes depending on their social capital. We tested the interaction effects for the salariat and those with degrees in the top level of each of the three types. The results show that none of the interaction terms are significant. The data are not reported here but are available on request.

13. We are grateful to one of the anonymous referees for alerting us to the possible bias in this regard. All details of further analysis are available upon request.

\section{Acknowledgements}

We wish to thank the Editor and the two anonymous referees, as well as Professors Robert Putnam, John Goldthorpe, Anthony Heath, Angela Dale, David Rose, Alan Warde, Tony Bennett, Fiona Devine, and seminar participants at Oxford, Manchester, Essex, Birmingham, Reading, York and Bristol universities for helpful comments and suggestions on earlier versions of this paper. We gratefully acknowledge the support of the Economic and Social Research Council (ESRC) for funding the project 'Social capital: developing a measure and assessing its value in social research' (R000223671) out of which this paper is a product. We are also grateful to the ESRC Data Archive for making the British Household Panel Survey (BHPS) data available to us. The BHPS was originally collected by the ESRC Research Centre on Micro-social Change at the University of Essex (now incorporated within the Institute for Social and Economic Research). Neither the original collectors of the data nor the Data Archive bear any responsibility for the analyses or interpretations presented here. We alone are responsible for any errors and mistakes in the paper.

\section{References}

Allan, G. (1996). Kinship and friendship in modern Britain. Oxford, UK: Oxford University Press.

Allan G. and Crow, G. (1993). Community Life. Brighton, UK: Harvester.

Anheier, H. and Kendall, J. (2002). Interpersonal trust and voluntary associations: examining three approaches. British Journal of Sociology, 53, 343-362.

Bechhofer, F. and Paterson, L. (2000). Principles of Research Design in the Social Sciences. London, UK: Routledge.
Bourdieu, P. (1986). The forms of capital. In Westport, J. (Ed.), Handbook of Theory and Research for the Sociology of Education. New York, NY: Greenwood, pp. 214-258.

Bourdieu, P. (1993). Sociology in Question. London, UK: Sage.

British Household Panel Survey [computer file] principal investigator, ESRC Research Centre on Microsocial Change, Colchester: The Data Archive [distributor], 2001. Data files and associated documentation.

Bromley, C., Curtice, J. and Seyd, B. (2001). Political engagement, trust and constitutional reform. In Park, A., Curtice, J., Thomson, K., and Bromley, C. (Eds) British Social Attitude: The $18^{\text {th }}$ BSA Report-Public Policy, Social Ties. London: Sage, pp. 199-225.

Bulmer, M. (1986). Neighbours: the work of Philip Abrams. Cambridge, UK: Cambridge University Press.

Burt, R. (1992). Structural Holes. Cambridge, MA: Harvard University Press.

Burt, R. (2000). The network structure of social capital. Research in Organisational Behaviour, 22, 345-423.

Burt, R. (2002). Bridge Decay. Social Networks, 24, 333-363.

Claibourn, M. and Martin, P. (2000). Trusting and Joining: an empirical test of the reciprocal nature of social capital. Political Behaviour, 22, 267-291.

Clark, W., Kahn, U. and McLaverty, P. (2002). Reformulating activism, reformulating the activist. Policy and Politics, 30, 455-468.

Cohen, L. and Holliday, M. (1982). Statistics for Social Scientists. London, UK: Harper \& Row.

Coleman, J. S. (1988). Social Capital in the Creation of Human Capital. American Journal of Sociology, 94, S95-S120.

Coleman, J. S (1990). Foundations of Social Theory. Cambridge, MA: Harvard University Press.

Field, J. (2003). Social Capital. London, UK: Routledge.

Fine, B. (2001). Social Capital versus Social Theory: Political economy and social science at the turn of the millennium. London: Routledge.

Frietag, M. (2003a). Beyond Tocqueville: The origins of social capital in Switzerland. European Sociological Review, 19, 217-232.

Freitag, M. (2003b). Social Capital in dissimilar democracies - the development of generalised trust in Japan and Switzerland. Comparative Political Studies, 36, 936-966.

Goldthorpe, J. H., Llewellyn, C. and Payne, C. (1987). Social Mobility and Class Structure in Modern Britain. Oxford, UK: Clarendon Press.

Granovetter, M. S. (1973). The strength of weak ties. American Journal of Sociology, 78, 1360-1380.

Hall, P. (1999). Social Capital in Britain. British Journal of Political Science, 29, 417-461. 
Harper, R. (2001). Social Capital: A review of the literature. London, UK: Office for National Statistics, Social Analysis and Reporting Division.

Inkeles, A. (2000). Measuring social capital and its consequences. Policy Sciences, 33, 245-268.

Jamieson, L. (1998). Intimacy: personal relationships in modern societies. Cambridge, UK: Polity.

Jenkins, S. P. (1999). Modelling Household Income Dynamics. ISER Working Paper 99-1: http://www.iser. essex.ac.uk/pubs/workpaps/pdf/1999-01.pdf.

Li, Y., Savage, M., Tampubolon, G., Warde, A. and Tomlinson, M. (2002). Dynamics of social capital: trends and turnover in associational membership in England and Wales: 1972-1999. Sociological Research Online, 7. http://www.socresonline.org.uk/7/3/Li.html

Li, Y., Savage, M. and Pickles, A. (2003). Social capital and social exclusion in England and Wales (19721999). British Journal of Sociology, 54, 497-526.

Lin, N., Ensel, W. and Vaughn, J. (1981). Social resources and the strength of ties: structural factors in occupational attainment. American Sociological Review, 46, 393-405.

Lin, N. (2001). Social Capital. Cambridge, UK: Cambridge University Press.

Lord, F. M. and Novick, M. R. (1968). Statistical theories of mental test scores. Reading, MA: Addison-Wesley.

Mayer, N. (2003). Democracy in France: do associations matter? In Stolle, D. and Hooghe, M. (Eds), Generating Social Capital: civil society and institutions in comparative perspective. Basingstoke, UK: Palgrave, pp 43-66.

Molenaers, N. (2003). Associations or informal social networks?: social capital and local development practices. In Stolle, D. and Hooghe, M. (Eds), Generating Social Capital: civil society and institutions in comparative perspective. Basingstoke, UK: Palgrave, pp: 89-112.

Newton, K. (1997). Social Capital and Democracy. American Behavioural Scientist, 40, 575-586.

Pahl, R. E. (2000). On Friendship. Cambridge, UK: Polity.

Parry, G., Moyser, G. and Day, N. (1992). Political Participation and Democracy in Britain. Cambridge, UK: Cambridge University Press.

Paxton, P. (1999). Is Social Capital Declining in the United States? A Multiple Indicator Assessment. American Journal of Sociology, 105, 88-127.

Paxton, P. (2002). Social capital and democracy: An interdependent relationship. American Sociological Review, 67, 254-277.

Portes, A. (1998). Social capital: its origins and applications in modern sociology. Annual Review of Sociology, 24, 1-24.
Putnam, R. D. (1993). Making democracy work: civic traditions in modern Italy. Princeton, NJ: Princeton University Press.

Putnam, R. D. (1995). Tuning In, Tuning Out: The Strange Disappearance of Social Capital in America. PS: Political Science and Politics, 28, 664-683.

Putnam, R. D. (1996). The Strange Disappearance of Civic America. American Prospect, 24, 34-48.

Putnam, R. D. (2000). Bowling alone: the collapse and revival of American community. New York, NY: Simon \& Schuster.

Rabe-Hesketh, S., Pickles, A. and Taylor, C. (2000). Generalized linear latent and mixed models. Stata Technical Bulletin, 53, 47-57.

Rabe-Hesketh, S., Skrondal, A. and Pickles, A. (2002). Reliable estimation of generalized linear mixed models using adaptive quadrature. The Stata Journal, 2, 1-21.

Roßteutscher, S. (2002). Advocate or Reflection: associations and political culture. Political Studies, 50, 514-528.

Rubin, D. B. (1976). Inference and missing data. Biometrika, 63, 581-592.

Schwartz, S. (1994). The fallacy of the ecological fallacy: the potential misuse of a concept and the consequences. American Journal of Public Health, 84, 819-824.

Stolle, D. (2003). The sources of social capital. In Stolle, D. and Hooghe, M. (Eds), Generating Social Capital: civil society and institutions in comparative perspective. Basingstoke, UK: Palgrave, pp: 19-42.

Stolle, D. and Hooghe, M. (Eds) (2003). Generating Social Capital: civil society and institutions in comparative perspective. Basingstoke, UK: Palgrave.

Szreter, S. (2002). The state of social capital: bringing back in power, politics and history. Theory and Society, 31, 573-621.

\section{Authors' Addresses}

Yaojun Li, Department of Sociology, Birmingham University, 32 Pritchatts Road, Birmingham B15 2TT, UK. Email: y.li.3@bham.ac.uk

Andrew Pickles, Centre for Census and Survey Research, Manchester University, Oxford Road, Manchester M13 9QS, UK. Email: andrew.pickles@man.ac.uk

Mike Savage, ESRC Centre for Research on SocioCultural Change, Manchester University, Manchester M13 9PL, UK. Email: mike.savage@man.ac.uk

Manuscript received: February 2004 
